\section{Blurred vision due to psychosocial difficulties: a case series}

development of the complaint. When no other organic pathology has been found, such patients are found to benefit from referral to liaison psychiatry or psychotherapy.

\section{Case reports}

Case I

Nina, a 12-year-old girl, complained of blurring and headaches while reading. She was not found to have any defect of the visual pathways or refractive error, but did have accommodative insufficiency $(18 \mathrm{~cm}$ near point of accommodation measured with the RAF rule binocularly and with each eye). She was given orthoptic exercises, but found no relief, and no significant objective improvement was found.

Her mother had suffered postnatal depression. She had come to the United Kingdom after war traumatised the family, and was concerned whether Nina might have undiagnosed psychiatric problems. Nina was referred to the consultant liaison child and adolescent psychiatrist.

Nina said that she was under pressure at school, and was the victim of systematic bullying. This centred on her appearance (she is overweight) and her religion.

The psychiatrist agreed that the blurring had an emotional basis and offered family meetings. Nina's mood improved dramatically. Her vitality returned when she knew that the bullying was being addressed, and her visual problems resolved.

The consultant liaison child and adolescent psychiatrist wrote to the referrer in the Eye Department to thank her for a most appropriate referral.

\section{Introduction}

Some cases of accommodative insufficiency have been found to have psychosocial difficulties, which played a role in the
Case II

Annie's mother was complaining that her daughter was flickering her eyelids. Annie also complained of difficulty seeing for near, 
headache, and stiff neck. She was behind with reading. She had insufficient accommodation (14-24 cm with the right eye, 22 the left, and 18 with both eyes). No other orthoptic and ophthalmological problems were found. However, Annie, an overweight girl, presented as bored and offhand. Her mother suffered from a chronic neurological disorder and her father had had a serious accident at work.

On subsequent visits, Annie's accommodation had not improved and her distance vision, previously fine, had deteriorated in the absence of any found physical cause. She was referred to the consultant liaison child and adolescent psychiatrist and Annie and her mother spoke about their traumatic experiences. On account of her mother's neurological disorder, four babies were lost during pregnancy. After her father's accident, Annie was physically bullied about his appearance.

The referral from the Eye Department to the consultant psychiatrist brought a speedy resolution of Annie's visual difficulties. On her last attendance at the Eye Clinic, Annie was seen smiling there for the first time and her accommodation was age-appropriate. Her reading had also improved.

\section{Case III}

Ruth, a 19-year-old university student, complained of blurring for near. This was interfering with her studies. She had limited accommodation $(25 \mathrm{~cm}$ binocularily and with each eye) but no refractive error or ophthalmological disorder. She had had glandular fever and stiff neck. She presented in a detached, cheerless manner.

She was given a course of orthoptic treatment. Her focusing improved slightly, but not sufficiently to be ageappropriate and to meet the demands of her studies. The question was posed whether her joylessness was related to her reading difficulty and she agreed that she was depressed and interested in being referred to a psychotherapy service.
She had six interviews to assess her need for psychotherapy. She subsequently came for an orthoptic appointment and started crying straight away. Her focusing had improved, but she had not decided whether she wanted psychotherapy. She asked to start the eye exercises again, but in a despairing way.

The Psychotherapy Assessment Report indicated that she had become tearful while discussing emotional issues, but was not able to acknowledge she was crying. Ruth explained that her 'eyes cry too easily'.

\section{Comment}

Henshall and Rowe ${ }^{1}$ have pointed out the association between psychological difficulties and accommodative anomalies, but did not continue to outline the next stage, the research and service development required to address these problems. However, patients and eye professionals often find it difficult to understand how there can be a psychosomatic translation between personal difficulties and ocular symptoms. We find it helpful to use the concept of alexithymia ${ }^{2}$ to recognise that some people cannot describe their emotional difficulties in words, and can only express them physically. Middleton ${ }^{3}$ has recommended joint management of such cases by both psychiatric and eye professionals to provide suitable psychological help. Developing the necessary referral pathways is a matter of good clinical governance, not simply a matter of local departmental interest.

\section{References}

1 Henshall VS, Rowe FJ. Diagnosis, aetiological and management considerations in accommodative insufficiency. Br Orthoptic J 2002; 59: 19-22.

2 Nemiah JC. Alexithymia and psychosomatic illness. J Cont Ed Psych 1978; 39: 25-37.

3 Middleton EM. The mind's eye: psychological aspects of eye disorders. Psychoanal Psychotherapy 1998; 12(2): 148-149. 